\title{
obituary
}

David M. Dennison died on April 3, 1976 at his home in Ann Arbor, Michigan. He was born on April 26, 1900 in Oberlin, Ohio, and, except for various leaves of absence, spent his whole academic career at the University of Michigan, where he joined the faculty in 1927. He was chairman of its Physics Department from 1955 to 1965 and retired in 1971 . He was a member of the National Academy of Sciences, a Fellow of the American Physical Society and the recipient of various honours.

With his death, the world of Physics loses again one of that small number of pioneer theorists who made early basic contributions to quantum mechanics and to the understanding of the structure of matter, contributions which today are regarded as self-evident. Dennison obtained his Ph.D. in 1924 from the University of Michigan, where Harrison M. Randall and coworkers were using powerful new techniques for the observation of the infrared spectra of molecules. Dennison then spent three years visiting various physics centres in Europe. In 1926, when he was in Cambridge studying with $\mathbf{R}$. H. Fowler, he proved that the hydrogen nucleus has a spin whose magnitude was half that of a quantum of rotation. That this nucleus might have a spin had been talked about widely, but no evidence had been presented. It is the more remarkable that Dennison's proof did not come from spectroscopic data, but from the study of a baffling anomaly in the variation with temperature of the specific heat of hydrogen. Dennison showed that the two configurations of the hydrogen molecule, one with parallel, the other with opposite nuclear spins, must be considered as two separate gases and that transitions from one into the other are very rare. This gave a complete quantitative explanation of the specific heat anomaly as well as a clarification of spectral data. That the volume ratio of the two gases had to be taken as three to one determined the value of the spin. The recognition of these two forms of hydrogen has today found an important use in the long-term storage of liquid hydrogen.

Another remarkable contribution made by Dennison in 1932 concerns the ammonium molecule $\mathrm{NH}_{3}$. In this molecule the nitrogen atom is in the centre of the triangle, but just outside the plane, formed by the three hydrogen atoms. Dennison noted that a quantum mechanical effect makes it possible for the nitrogen to 'leak' through to the other side. The details were worked out in collaboration with G. E. Uhlenbeck, also at Michigan. It was shown that this non-classical effect caused the molecule to absorb radiation of $\sim 1.5-\mathrm{cm}$ wavelength, which might be produced by miniature magnetrons. Dennison inspired N. H. Williams and C. E. Cleeton at Michigan to attempt a unique experiment to detect this absorption. It was successful and represents the first experiment in microwave spectroscopy. During the second world war, Dennison collaborated with a group developing proximity fuses. Afterwards he spent some time together with T. H. Berlin computing orbits for the Michigan electron accelerator, though his primary interest remained the quantum theory of molecular structure and the interpretation of their spectra to which he contributed many important advances.

David Dennison was an excellent teacher with a genuine concern for students. He was a modest person, who never lost his temper and had many interests outside the field of physics.
He was a fine scholar, a helpful friend with whom it was a great and beneficial pleasure to discuss all sorts of problems.

\section{Samuel A. Goudsmit}

Hans Thirring, Professor emeritus at Vienna University, died on March 22, 1976. He held the chair of Theoretical Physics from 1927 to 1958 , except during the time of the Nazi regime when he was dismissed because of his pacifist convictions.

Thirring's scientific work dealt mainly with problems in general relativity. The prediction of the 'Thirring-Lense effect' is widely known. He also made important contributions to the quantum theory of specific heats. His 3-yr course on theoretical physics was an excellent example of how to present complicated material in a crystal clear way, and many generations of young physicists profited greatly from his outstanding teaching.

During World War 2 Thirring's thinking concentrated on the question how to achieve a peaceful world. The horrific prospects of nuclear warfare stimulated his activities. Thirring was the first to predict openly the feasibility of a hydrogen bomb, in his book Die Geschichte der Atombombe (1946). His further book, Homo Sapiens, outlined an educational and psychological way to a world without aggression, hatred and war. He was realist enough to expect not too much effect on mankind from the written word alone, and be put his convictions into practice. $\mathrm{He}$ was one of the pioneers of the Pugwash movement and he considered this free community of scientists of high reputation from all nations as one of the few hopeful developments towards peace in his time and for the future.

P. Weinzierl

\section{announcements}

\section{Appointments}

Professor Frans E. Wickman has been elected President of the Royal Swedish Academy of Sciences.

Dr A. Bull has been appointed to the second Chair in Applied Biology at the University of Wales, Cardiff.
Dr Ernest Ambler has been appointed the new Director of the National Bureau of Standards.

Professor Robert F. Whelan has been appointed Vice-Chancellor of the University of Liverpool.

Professor Francois Gros has been appointed as Director of the Institut

\section{Pasteur.}

Dr Donald D. Brown will become the Director of the Carnegie Institution of Washington's Department of Embryology to succeed Dr James D. Ebert who is moving to the Marine Biological Laboratory in Woods Hole as the fulltime President and Director. 